\title{
Medicinal and Pharmaceutical Applications of Mucin and its Derivatives
}

ISSN: 2576-9170

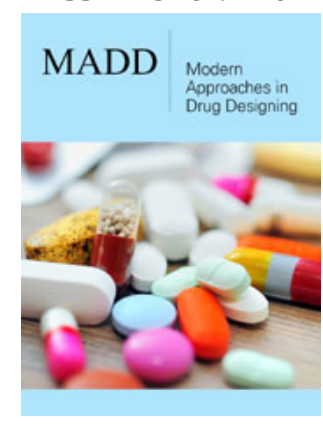

*Corresponding author: Adikwu MU, Department of Pharmaceutics, Faculty of Pharmaceutical Sciences, Nsukka, Nigeria

Submission: 眥September 16, 2019

Published: 毕September 25, 2019

Volume 2 - Issue 4

How to cite this article: Adikwu MU. Medicinal and Pharmaceutical Applications of Mucin and its Derivatives. Mod Appro Drug Des.2(4). MADD.000543.2019. DOI: 10.31031/MADD.2019.02.000543.

Copyright@ Adikwu MU, This article is distributed under the terms of the Creative Commons Attribution 4.0 International License, which permits unrestricted use and redistribution provided that the original author and source are credited.

\author{
Adikwu MU* \\ Department of Pharmaceutics, Faculty of Pharmaceutical Sciences, Nigeria
}

\section{Introduction}

The interest of my work on mucins, particularly snail mucin, started as an Alexander von Humboldt Fellow in Germany, where I watched slugs survive in a terribly cold environment. I was carrying out a research on modelling of some charge-transfer complexes. I had wanted to change my research into looking at some of the biochemical factors that could make slugs survive under such environmental conditions. Apart from the survival processes, slugs are "raw" flesh crawling on the bare earth and do not get destroyed by bacteria or other infective agents. I was, however, not allowed as I had a contract with the Foundation on what I should do at that period. When I returned, my interest on mucins multiplied and has been my focus of research for some time now.

Slugs belong to the family of animals called the Gastrpoda [1]. This class includes the common land snails and they are generally called mollusks. They possess good biochemical properties which are of pharmaceutical and medicinal importance. As mentioned above, apart from the capacity of their mucins to protect them in the winter through cyst formation, they also protect the animals against attack by microorganisms. In an editorial that I wrote for a journal [2], I had mentioned that mucins are the major macromolecular constituents of the mucous secretions that coat the oral cavity and the respiratory, gastrointestinal and urinogenital tracts of animal. They are responsible for the viscoelastic properties of the secretions, providing protection for the exposed delicate epithelial surfaces from microbial and physical injuries. Secretory mucins are typically of very high molecular mass (over $1 \mathrm{mDa}$ ) and have hundreds of 0 -linked saccharides constituting between $50 \%$ and $80 \%$ of the molecule by weight [3]. The saccharides are based, at present, on seven core structures and can vary in length from disaccharides to oligosaccharides of approximated 20 monosaccharides and exhibit astonishing diversity.

The biological relevance of this diversity is not fully understood, but one possibility is that they act as 'decoy' receptors for the prevention from binding of pathogens to epithelial cell. It has been shown for a long time that the saccharides are linked to serine and threonine residues of the protein scaffold. However, owing to the technical problems associated with deglycosylation of mucins, the biochemical characterization of the protein backbone of the large discrete mucins has been fraught with difficulties. Mucins play a key role in the host intestine. From acting as a protective, physical barrier, they are responsible for producing certain protective enzymes that are responsible for the host intestinal defensive mechanism. The defensins and magainin's that protect the host in the intestine are largely responsible for the prevention of many microbial diseases [4-7]. The integrity of the intestinal mucin may also help as a physical barrier to the entrance of bacteria to the underlining tissue (Figure 1). Thus, organisms that produce enzymes capable of hydrolyzing mucins can easily establish infections. Thus, the microorganisms that produce sialidases are capable of hydrolyzing cervical mucin and such organisms have been implicated in the pathogenesis of sexually transmitted infections in the female genital tract. Hence, the detection of these enzymes may be indicative of the presence of invading organisms and may be used as a diagnostic tool. Mucins may play a key role in the pharmaceutical industry as a drug delivery agent if properly harnessed [8-13]. 


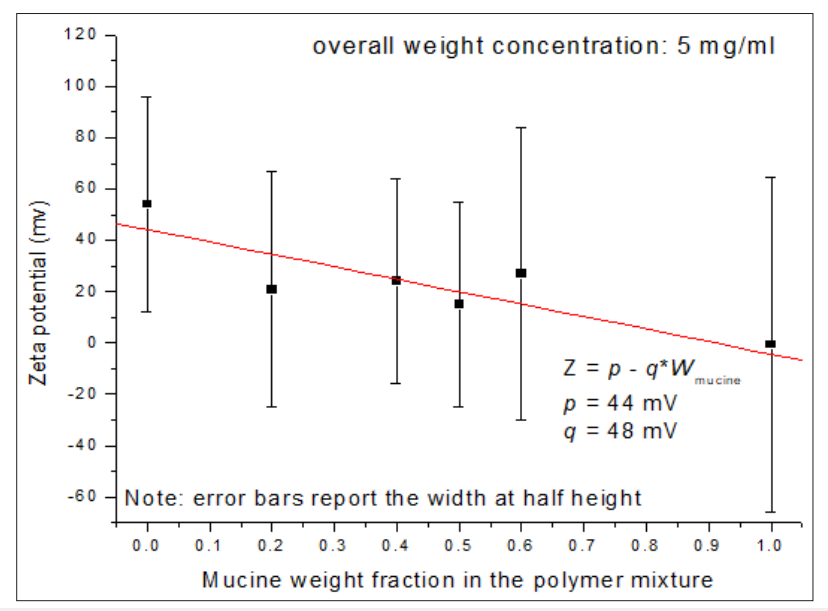

Figure 1: Mathematical relationship between zeta potential and mucin concentration in the system.

\section{Conclusion}

Mucins have been shown to have great potentials in wound healing and as carrier agents for pharmaceutical bio actives. It should be known that I was the first to conceive mucin as a carrier agent for these molecules. It should also be known that there is great future on the research on mucins as it seems as no cell can thrive without these molecules $[14,15]$.

\section{References}

1. https://en.wikipedia.org/wiki/Slug

2. Adikwu MU (2006) Mucins and their potentials (editorial). Tropical Journal of Pharmaceutical Research 5(2): 581-582.

3. Adikwu MU (2005) Evaluation of snail mucin motifs as rectal absorption enhancer for insulin in non-diabetic rat models. Biological and Pharmaceutical Bull 28(9): 1801-1804.

4. Adikwu MU, Audu-Peter JD (2006) Adsorption of Staphylococcus aureus onto bovine intestinal mucin. Paper presented at the $7^{\text {th }}$ Annual Scientific
Conference of Nigerian Association of Pharmacists in Academics (NAPA), Ahmadu Bello University Zaria, Nigeria, pp. 19-22.

5. Adikwu MU Ikejiuba CC (2005) Some physicochemical and wound healing properties of snail mucin. Bolletino Chimico Farmceutico 144: 1-8.

6. Adikwu MU, and Ndu OO (2006) Gastroprotective properties of mucin and honey combinations. Journal of Pharmaceutical Research (India) 5: 84-86.

7. Adikwu, MU, Nnamani PO (2005) Some physiological and toxicological properties of snail mucin. Bioresearch 5: 1-6.

8. Momoh MA, Adikwu MU, Ibezim EC, Ofokansi KC, Attama AA (2010) Thermal characterization of PEGylated mucin. Asian Pacific Journal of Tropical Medicine 12: 1-4.

9. Ofokansi KC, Okorie O, Adikwu MU (2009) Biodegradable microspheres based on gelatin-porcine mucin admixtures: In vitro and in vivo delivery studies. Biol Pharm Bull 32(10): 1754-1759.

10. Ofokansi KC, Adikwu MU (2007) Formulation and evaluation of microspheres based on gelatin-mucin admixtures for rectal delivery of cefuroxime sodium. Trop J Pharm Res 6(4): 825-832.

11. Ofokansi KC, Adikwu MU, Okore VC (2007) Preparation and evaluation of mucin-gelatin mucoadhesive microspheres for rectal delivery of ceftriaxone sodium. Drug Dev Ind Pharm 33(6): 691-700.

12. Adikwu MU, Okafor JO (2006) Evaluation of mucin as a release enhancer for rectal delivery of glibenclamide. Current Drug Delivery 3 (3): 243254.

13. Adikwu MU (2006) Report submitted to the Royal Society, London, UK.

14. Cheney S (1988) Raising snails. reference branch, United States department of agriculture, The National agricultural Library Beltsville, Maryland, USA.

15. Wei GX, Bobek (2005) Human salivary mucin MUC12-mer-L and 12-mer-D peptides: Antifungal activity in saliva, enhancement of activity with protease inhibitor cocktail or EDTA, and cytotoxicity to human cells. Antimicrobial Agents Chemotherapy 49(6): 2336-4232. 